\title{
FFHD
}

Functional Foods in Health and Disease

\section{Suppression of blood glucose level elevation and promotion of GLP-1 secretion by ingestion of Undaria pinnatifida sporophylls (Mekabu): Open-label crossover design}

\author{
Shiori Takano ${ }^{1}$, Kazuma Yoshizumi², Hitomi Kobayashi ${ }^{3}$, Naoki Iwamoto ${ }^{4}$, Masaki Taga ${ }^{{ }^{*}}$ \\ ${ }^{1}$ Faculty of Human Ecology, Wayo Women's University, Ichikawa, Chiba 272-8533, Japan; ${ }^{2}$ Kaneryo Sea Vegetable \\ Corporation, Uto, Kumamoto, 869-0402, Japan; ${ }^{3}$ Faculty of Human Nutrition, Seitoku University, Matsudo, Chiba, 271-8555, \\ Japan; ${ }^{4}$ Faculty of Contemporary Human Life Science, Tokyo Kasei Gakuin University, Machida, Tokyo, 194-0292, Japan
}

*Corresponding Author: Masaki Taga, PhD, Faculty of Human Ecology, Wayo Women's University, Ichikawa, Chiba 2728533, Japan

Submission Date: January 12 ${ }^{\text {th }}$, 2022; Acceptance Date: February 14 $4^{\text {th }}, 2022$; Publication Date: February $16^{\text {th }}, 2022$

Please cite this article as: Takano S., Yoshizumi K., Kobayashi H., Iwamoto N., Taga M. Suppression of blood glucose level elevation and promotion of GLP-1 secretion by ingestion of Undaria pinnatifida sporophylls (Mekabu): Open-label crossover design. Functional Foods in Health and Disease 2022; 12(2): 93-102. DOI: https://www.doi.org/10.31989/ffhd.v12i2.891

\section{ABSTRACT}

Background: It has been confirmed that the daily consumption of seaweed such as Wakame (Undaria pinnatifida) and Kombu (Saccharina japonica) has an inhibitory effect on the rise in postprandial blood glucose levels. Similar effects can also be expected for Mekabu, which is Wakame sporophylls and contains large quantities of water-soluble dietary fiber. In this study, we examined the effects of preprandial intake of Mekabu on postprandial blood glucose levels and blood glucose regulation-related hormones in healthy young women.

Methods: The subjects were ten healthy young adult women. Mekabu was eaten, followed by rice only. Blood was sampled five times: while fasting ( $0 \mathrm{~min})$, and $15,30,90$, and 120 minutes after eating. Measurements were taken of blood glucose level and blood glucose regulation-related hormones.

Result: Eating Mekabu before rice resulted in a significant reduction of $\Delta$ glucose and $\Delta$ insulin at 30 minutes after ingestion ( $p=0.034, p=0.049$, respectively). The level of glucagon-like peptide-1 (GLP-1) in plasma was higher 30 minutes after eating $(p=0.044), 60$ minutes $(p=0.031)$, and 120 minutes $(p=0.019)$ when Mekabu was eaten preprandially. 
Conclusions: In the present study, GLP-1 secretion was sustained by eating Mekabu, which is Wakame sporophylls, before rice. Our results suggest that ingesting Mekabu, which contains large amounts of viscous alginic acid, prior to a meal not only suppresses postprandial blood glucose level, but supports the extended secretion of GLP-1, providing a sustainable incretin effect.

Keywords: mekabu (Undaria pinnatifida sporophylls), blood glucose, glucagon-like peptide-1 (GLP-1), insulin, incretin, water-soluble dietary fiber

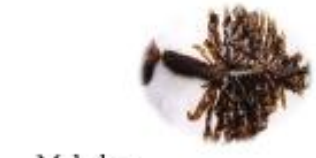

Mekabu

(Undaria pinnatifida sporophylls)

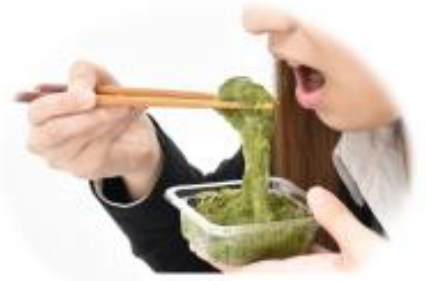

Eat Mekabu at the beginning

of a rice
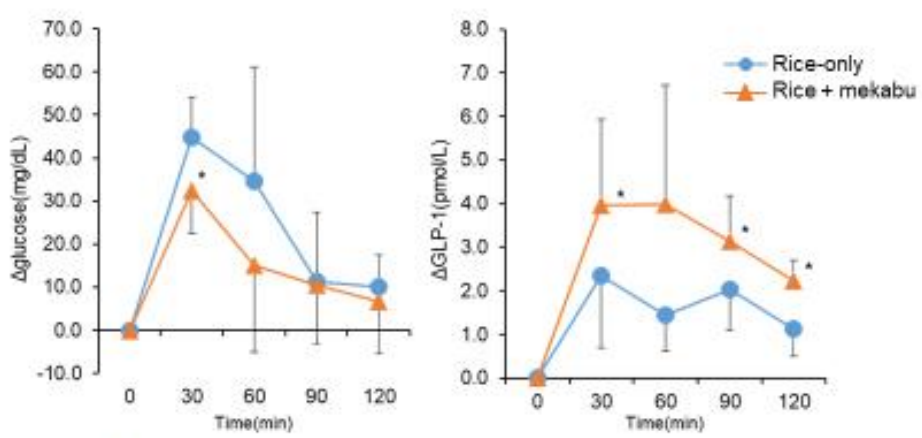

Pre-meal intake of mekabu suggested postprandial blood glucose suppression and sustained GLP-1 secretion.

(C) FFC 2022. This is an Open Acess article distributed under the terms of the Creative Commons Attribution 4.0 License (http://creativecommons.org/licenses/by/4.0)

\section{INTRODUCTION}

According to the 2021 report of the International Diabetes Federation (IDF), the number of diabetes patients worldwide is about 537 million, corresponding to about $10 \%$ of the adult population. Without effective countermeasures, the number of people with diabetes is expected to rise to about 783 million by 2045 [1].

Diabetes is characterized by a chronic hyperglycemic state due to a decrease in insulin secretion and lack of insulin action, which causes various metabolic anomalies. Diabetes is broadly classified into type 1 diabetes and type
2 diabetes. Type 1 diabetes is an autoimmune disease that causes low insulin secretion due to loss of the beta cells of the pancreas. The numbers of Type 2 diabetes patients are increasing due to lifestyle-related habits, such as an unbalanced diet and lack of exercise, or a lack of insulin action due to stress and genetic predisposition: the resultant insufficient insulin secretion from the pancreatic beta cells causes the onset of diabetes. About $90 \%$ of diabetes patients have Type 2 diabetes [1]. Type 2 diabetes is closely related to diet, so one important strategy for its prevention is to improve diet and exercise habits. A rapid 
rise in blood glucose levels after meals is implicated in the onset and progression of diabetes. Blood glucose control is important to reduce the rapid rise of postprandial blood glucose levels caused by diet. On the other hand, glucagonlike peptide-1 (GLP-1), which is an incretin hormone, is a digestive tract hormone, secreted from the distal small intestine, that stimulates the secretion of insulin in response to high blood glucose levels [2]. GLP-1 is secreted only when blood glucose levels are high, reducing the risk of hypoglycemia. Because of their low risk of causing hypoglycemia, dipeptidyl peptidase-4 (DPP- 4) inhibitors, which destroys; DPP-4 inhibitors do not destoy incretins, DPP-4 destory incretins.

In recent years, it has become clear that the order in which food is eaten affects the postprandial blood glucose level rise. Eating vegetables that contain a large amount of dietary fiber before eating staple foods, i.e., by adopting a "Vegetables First" strategy, makes it possible to suppress the rapid rise of postprandial blood glucose levels. This practice is reported to improve the $\mathrm{HbA} 1 \mathrm{c}$ value in diabetic patients [3-4]. The same effect is confirmed by eating both vegetables and meat, fish, etc [5-6].

Similar effects have been identified for Wakame (Undaria pinnatifida), which also contains a great deal of dietary fiber [7]. It has been reported that water-soluble dietary fiber such as fucoidan and alginic acid contained in brown algae such as wakame and kombu (Saccharina japonica) also has an inhibitory effect on blood glucose level rise[8-9].In recent years, the market in Japan for Mekabu as a food has grown rapidly. Mekabu is a sporophylls part of Wakame and containing large quantities of highly viscous alginic acids and fucoidans, which are water-soluble dietary fibers that appear to suppress the increased blood glucose level seen after meals. However, there are few reports on the effects of eating raw Mekabu on blood glucose regulation-related hormones and biomarkers.

In this study, we examined the effects of preprandial intake of raw Mekabu on postprandial blood glucose levels and blood glucose regulation-related hormones in healthy young women.

\section{SUBJECTS AND METHODS}

1. Subjects: In this study, the exclusion criteria were as follows: fasting blood glucose level $>110 \mathrm{mg} / \mathrm{dL}$ and Homeostatic Model Assessment for insulin resistance (HOMA-IR) reaging > 1.6. The subjects were 10 healthy young adult females aged 20 - 23 years with fasting blood glucose of below $110 \mathrm{mg} / \mathrm{dl}$, as measured in advance by self-monitoring of blood glucose. Blood was then collected from the ten individuals and tested using HOMA-IR. Three of the women, who gave a HOMA-IR reaging of 1.6 or more, were excluded.

2. Test foods: Commercially marketed rice (Sato Foods Co., Ltd., Niigata, Japan) and $40 \mathrm{~g}$ of commercial Mekabu (Kaneryo Sea Vegetable Corporation, Uto, Kumamoto, Japan) processed using the Takaki Heating and Cooling (THC) System employed by Takaki Shoten Corporation (Uto, Kumamoto, Japan) were used as the test foods.

The THC system is a heating and sterilization method of processing Mekabu by passing an electrical current through it. Unlike the conventional steam heat sterilization method, it preserves the color, flavor and texture of Mekabu, and minimizes any loss of nutritional components. The nutritional ingredients of each test food are shown in Table 1. In addition, the details of dietary fiber in Mekabu are shown in Table 2 
Table 1. Composition of test foods

\begin{tabular}{|l|c|c|}
\hline Weight (g) & Rice & +Mekabu \\
\hline Energy (kcal) & 200 & 40 \\
\hline Protein (g) & 296 & 6.9 \\
\hline Fat (g) & 4.8 & 0.5 \\
\hline Carbohydrate (g) & 0.0 & 0.2 \\
\hline Dietary fiber (g) & 67.6 & 1.1 \\
\hline
\end{tabular}

Table 2. Dietary fiber content in Mekabu

\begin{tabular}{|c|c|}
\hline & Content (g/40g of raw Mekabu) \\
\hline Total dietary fiber ${ }^{1}$ & 1.0 \\
\hline Water-soluble dietary fiber ${ }^{2}$ & 0.8 \\
\hline Alginic acid & 0.6 \\
\hline Fucoidan & 0.2 \\
\hline Insoluble dietary fiber & 0.2 \\
\hline
\end{tabular}

${ }^{1}$ Total quantity of dietary fiber is the sum of the amount of water-soluble dietary fiber and the insoluble dietary fiber.

2 Total quantity of water-soluble dietary fiber is the sum of the amount of alginic acid and fucoidan.

3. Protocol: The present study was conducted using an open-label crossover design. The same subjects consumed rice (the Rice only ) or consumed rice after ingesting Mekabu (the Mekabu + rice). Both test were conducted two week apart. The subjects were instructed not to consume any food or drinks other than water between 10:00 pm on the day before the test and the start of the test. Investigations started a 9:30 am, and during the two-hour test, the subjects were instructed to rest at the site. Exercise was prohibited. In all the tests, the time when rice (200 g) consumption started was designated as 0 minutes. Mekabu (40 g) was eaten five minutes prior to rice consumption by the Mekabu + rice. The rice was to be fully consumed within 10 minutes. Blood was collected from the forearm median cutaneous vein five times: during fasting (0 $\mathrm{min}$ ) and 30, 60, 90, and 120 minutes after the rice had been eaten. Plasma blood glucose level, serum insulin, and plasma active GLP-1 were measured each time, with the $\mathrm{HbA1c}$ (NGSP value) measured once, at 0 minutes.

4. Blood analysis: Blood analysis was commissioned to SRL Co., Ltd. (Tokyo, Japan), and was performed in accordance with SRL's quality control procedures. Glucose levels are measured using the hexokinase UV method. Insulin 
concentrations are measured using the chemiluminescent enzyme immunoassay (CLEIA) method, and GLP-1 levels are measured using the enzyme-linked immunosorbent assay (ELISA) method. HOMA-IR was calculated using the formula: fasting blood glucose levels $\times$ fasting insulin concentrations / 405.

\section{Statistical analysis: Blood glucose levels after consuming} rice, insulin, and GLP-1 were subtracted from the 0-minute value as degree of change, $\Delta$ blood glucose level, $\Delta$ insulin, and $\triangle G L P-1$. The degree of change was calculated using a trapezoidal formula based the degree of change and the dynamic parameters of blood glucose, insulin, and GLP-1. Each set of data items was treated as an average value \pm SD (standard deviation). To assess the effectiveness of Mekabu intake, for blood glucose levels, insulin concentrations, and GLP-1 levels, a corresponding t-test was performed between the rice only and the Mekabu + rice at each blood collecting time based on the rice only as control. For $\triangle A U C$, a paired t-test was performed between the rice only and the Mekabu + rice. Statistical processing was performed using SPSS Statistics Ver. 26 (IBM, Japan), and the level of two-side significance was set at less than $5 \%$ in all data.

6. Ethical considerations: The present study was conducted according to the guidelines laid down in the Declaration of

Table 3. Characteristics of the subjects
Helsinki (adopted in 1964, final revision of October 2013), and all procedures involving human subjects were approved by Wayo Women's University Ethics Committee (Authorization Number 1801; Approval date: 13 June 2018). It was explained to the subjects that they would not be disadvantaged in any way by participating in, not participating in, or withdrawing from the study. Its purpose and expected effects were described. We carefully explained about protection of personal information, both verbally and in written form. After it was clear that the subjects fully understood these details, each signed the document.

\section{RESULTS}

1. Subjects: All of the seven subjects, excluding three subjects with HOMA-IR reaging of 1.6 or more, completed the study and consumed all the test meals entirely without problems. During the test period, no adverse effects were observed. The average age of the subject was $21.4 \pm 1.0$ years. The average body mass index (BMI) of the subject was $19.2 \pm 1.6 \mathrm{~kg} / \mathrm{m}^{2}$, the average fasting blood glucose was $92.7 \pm 11.0 \mathrm{mg} / \mathrm{dl}$, and the average $\mathrm{HbA1c}$ was $5.2 \pm 0.3 \%$. No subjects showed abnormal blood glucose control. HOMA-IR was $1.2 \pm 0.2$, and no unusual insulin sensitivity was observed (Table 3).

Content $(\mathrm{g} / 40 \mathrm{~g}$ of raw Mekabu)

\begin{tabular}{|l|l|}
\hline Age (year) & $21.4 \pm 1.0$ \\
\hline Height (cm) & $159.3 \pm 5.4$ \\
\hline Weight (kg) & $48.7 \pm 4.3$ \\
\hline BMI (kg/m²) & $19.2 \pm 1.6$ \\
\hline Fasting blood glucose (mg/dL) & $92.7 \pm 11.0$ \\
\hline HbA1c (\%) & $5.2 \pm 0.3$ \\
\hline HOMA-IR & $1.2 \pm 0.2$ \\
\hline
\end{tabular}

Seven subjects, excluding three subjects with HOMA-IR reaging exceeding 1.6 or more 
2. Plasma glucose responses: The postprandial plasma glucose and $\triangle \mathrm{AUC}$ of plasma glucose responses after consumption of the test foods are shown in Figure 1. Postprandial blood glucose level, insulin concentration and GLP-1 level were compared between the Rice-only and the Mekabu + rice for all seven subjects. The blood glucose levels at the beginning of the study $(0 \mathrm{~min}$ ) were $89.3 \pm 5.7$ $\mathrm{mg} / \mathrm{dL}$ in the Rice-only and $90.4 \pm 4.4 \mathrm{mg} / \mathrm{dL}$ in the Mekabu + rice. In both meals, blood glucose levels increased rapidly after test food intake, peaked at 30 minutes, and then declined (Fig. 1A). A significant difference, however, was observed in the Mekabu + rice, who showed lower values at 30 and 60 minutes after the start of rice consumption than the Rice only. Although $\Delta$ blood glucose level peaked 30 minutes after the start of intake, it showed a lower value in the Mekabu + rice $(32.4 \pm 10.1 \mathrm{mg} / \mathrm{dL})$ than in the Riceonly $(44.7 \pm 9.4 \mathrm{mg} / \mathrm{dl})(p<0.05)$ (Fig. 1B). The blood glucose level, $\triangle A U C$, calculated from Fig. 1B, was also significantly lower in the Mekabu + rice $(1980.0 \pm 1144.5$ $\mathrm{mg} \cdot \mathrm{min} / \mathrm{dl})$ than in the Rice-only $(2907.9 \pm 1272.2$ $\mathrm{mg} \cdot \min / \mathrm{dl})(p<0.05)$, as shown in Figure $1 \mathrm{C}$.
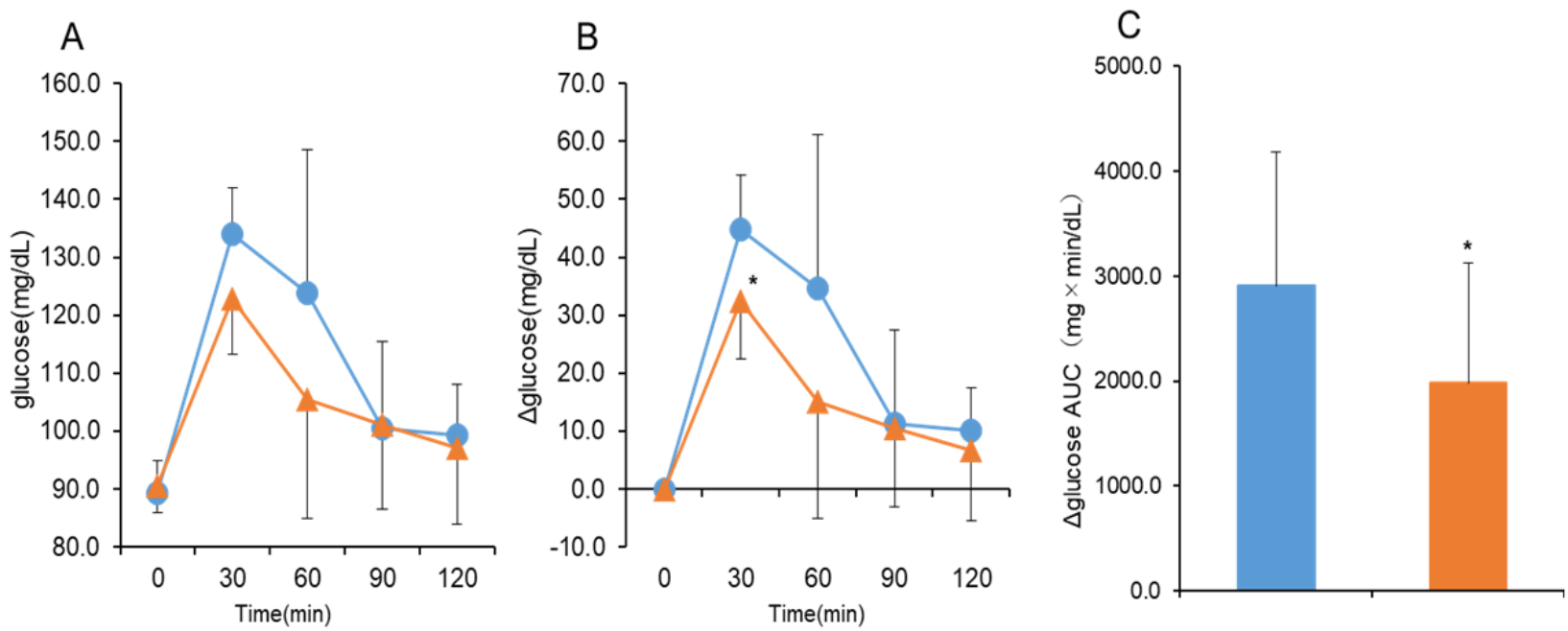

Figure 1: Time course curves for glucose (A) and $\Delta$ glucose (B) during the two different meal sequences. Rice-only, blue circle; Mekabu + rice, orange triangle $(A, B)$. (C): Glucose $\triangle A U C$. Rice only, blue bar; Mekabu + rice, orange bar). The data were analyzed by t-test; ${ }^{*} \mathrm{p}<0.05$ was regarded as indicating a statistically significant difference between the meals.

3. Serum insulin responses: Average insulin value before eating rice $(0 \mathrm{~min})$ was $5.2 \pm 1.4 \mu \mathrm{IU} / \mathrm{ml}$ in the Rice-only and $5.8 \pm 0.9 \mu \mathrm{lU} / \mathrm{ml}$ in the Mekabu + rice . In all the tests, the insulin concentration rose rapidly after consuming rice, peaking within 30 minutes and then decreasing. Thirty minutes after eating the test foods, the insulin concentration was significantly lower in the Mekabu+rice $(44.3 \pm 16.8 \mu \mathrm{iU} / \mathrm{ml})$ than the Rice-only $(56.9 \pm 28.1 \mu \mathrm{iU} / \mathrm{ml})$ $(p<0.05)$ (Fig. 2A). The $\Delta$ insulin concentration also showed significantly lower values in the Mekabu + rice $(38.5 \pm 16.9$ $\mu \mathrm{ML} / \mathrm{mL})$ than the Rice-only $(51.8 \pm 27.6 \mu \mathrm{lU} / \mathrm{ml}) 30$ minutes after the start of the test foods $(p<0.05)$ (Fig. 2B). Insulin $\triangle \mathrm{AUC}$ showed a lower value in the Mekabu + rice $(3219.0 \pm 534.3 \mu \mathrm{lU} \cdot \mathrm{min} / \mathrm{ml})$ than the Rice-only $(3827.8 \pm$ $1512.2 \mu \mathrm{IU} \cdot \mathrm{min} / \mathrm{mL})$, but no significant difference was observed between each test (Fig. 2C). 

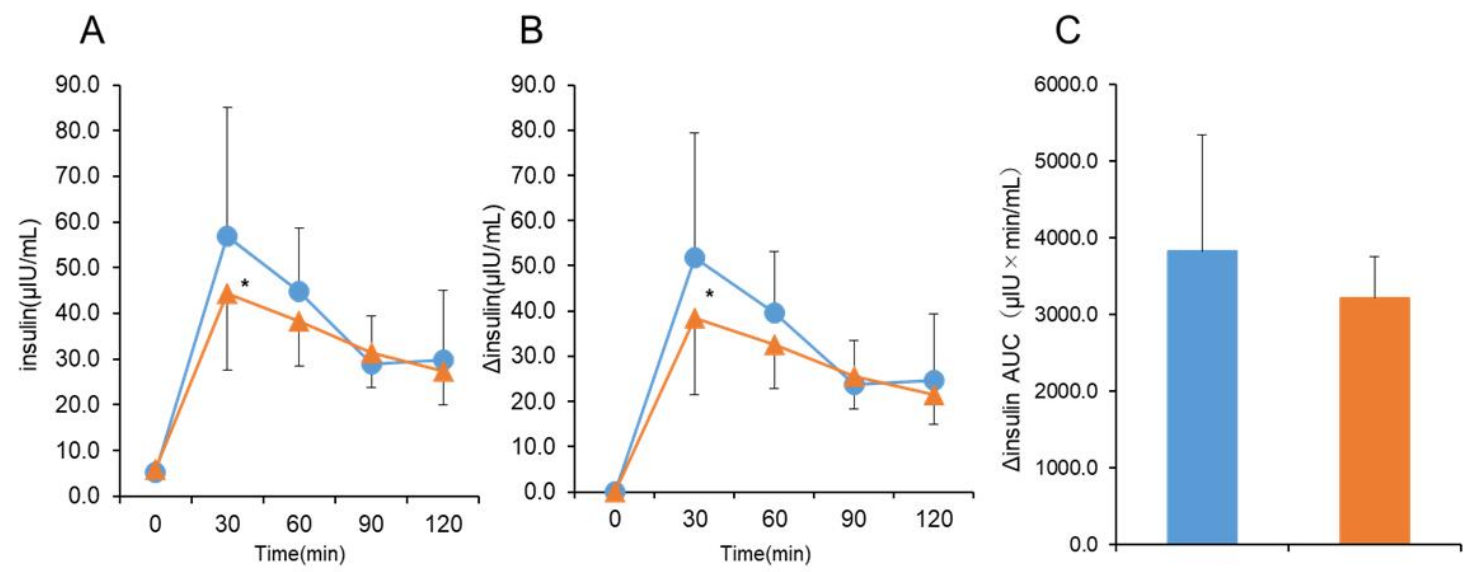

Figure 2: Time course curves for insulin (A) and $\Delta$ insulin (B) during the two different meal sequences. Rice-only, blue circle; Mekabu + rice, orange triangle (A, B). (C): Insulin $\triangle A U C$. Rice-only, blue bar; Mekabu + rice, orange bar). The data were analyzed by t-test; ${ }^{*} p<0.05$ was regarded as indicating a statistically significant difference between the meals.

4. Plasma intact glucagon-like peptide-1 (GLP-1) responses: Changes in GLP-1 levels after rice consumption are shown in Figure 3. Its value before the pre-test foods (0 $\mathrm{min}$ ) was $1.5 \pm 0.6 \mathrm{pmol} / \mathrm{L}$ in the Rice-only, and $1.6 \pm 0.7$ $\mathrm{pmol} / \mathrm{L}$ in the Mekabu + rice. GLP-1 did rise in either group after consumption of rice. It showed a maximum value after 30 minutes and then declined. It was significantly higher in the Mekabu + rice than the Rice-only at 30,60, and 90 minutes after rice consumption (all $p<0.05$ ). In addition, although no significant difference was observed in GLP-1 levels even 90 minutes after rice consumption, it showed a higher value in the Mekabu + rice (Fig. 3A). Similarly, the $\triangle$ GLP-1 value was significantly higher in the Mekabu+rice than the rice only at 30,60 , and 120 minutes after rice consumption $(p<0.05)$ as shown in Fig 3B. In the Mekabu + rice, the GLP-1 level declined slowly for up to 120 minutes after the start of rice consumption. The GLP-1 $\triangle A U C$, calculated based on Fig. 3B was significantly higher in the Mekabu + rice $(269.6 \pm 93.4 \mathrm{pmol} \cdot \mathrm{min} / \mathrm{L})$ than the Rice-only $(154.4 \pm 65.9 \mathrm{pmol} \cdot \mathrm{min} / \mathrm{L})(p<0.05)$.
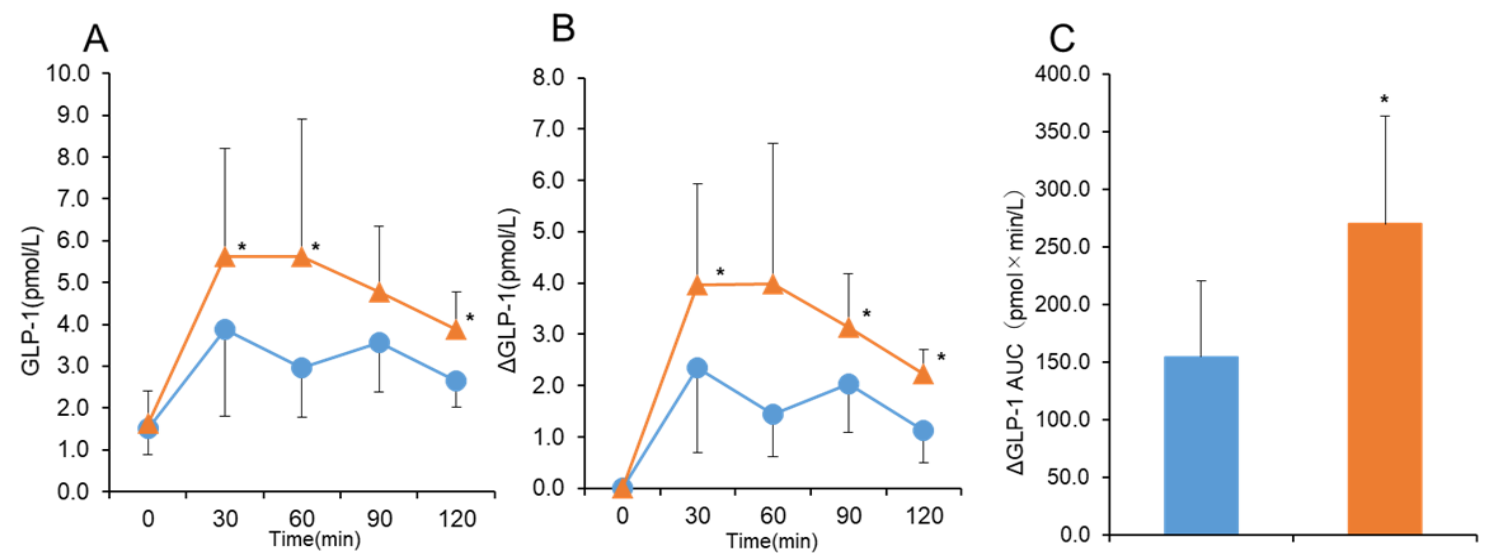

Figure 3: Time course curves for in GLP-1 (A) and $\triangle$ GLP-1 (B) during the two different meal sequences. Rice-only, blue circle; Mekabu + rice, orange triangle (A, B). (C): GLP-1 $\triangle A U C$ values. Rice-only, blue bar; Mekabu + rice, orange bar). The data were analyzed by t-test. ${ }^{*} p<0.05$ was regarded as indicating a statistically significant difference between the meals. 


\section{DISCUSSION}

This study examined, using an open-label cross-over design test, the postprandial blood glucose level suppressive effect and influence on blood glucose regulation-related hormones of Mekabu, which contains large quantities of water-soluble dietary fiber. Our results showed that preprandial intake of Mekabu significantly suppressed the rise in blood glucose levels 30 minutes after rice consumption. Wakame, a brown algae, and its sporophylls, Mekabu, are rich in water-soluble dietary fibers such as alginic acid and fucoidan that are reported to significantly suppress blood glucose levels [10].

The suppression of blood glucose levels seen in this test also suggests that absorption of sugars by the intestine is inhibited by the intake of alginic acid and fucoidan that is present in the viscous components of Mekabu. Serum insulin concentration 30 minutes after consuming rice was also significantly lower in the Mekabu+rice. We conclude that because the subjects showed no abnormalities in their saccharide metabolism, this case also showed a normal insulin response to fluctuations in blood glucose levels. Furthermore, at all times after rice consumption, the plasma value of GLP-1 was significantly higher in the Mekabu + rice than in the Rice-only. GLP-1 is a type of incretin, a digestive tract hormone secreted from the $L$ cells in the distal small intestine when stimulated by the presence of lipids and carbohydrates [11]. Secreted GLP-1 binds to the GLP-1 receptors in the beta cells of the pancreatic Islands of Langerhans such that insulin is secreted in response to raised glucose levels in the blood. Secreted GLP-1 is rapidly degraded and inactivated by DPP4 present in the blood, so GLP-1 rarely remains high after a meal.

However, in this study, the value of plasma GLP-1 in the Mekabu + rice was maintained at a higher level than seen in the Rice-only for up to 120 minutes after rice consumption. It appears likely that the absorption of sugars from the intestine is suppressed by Mekabu intake. Sugars are slowly absorbed for 120 minutes after rice consumption and it is presumed that stimulation of the $L$ cells continues. When a healthy person consumes an $\alpha$-glucosidase inhibitor, postprandial blood glucose levels decrease rapidly, and the secretion of plasma GLP-1 continues for up to four hours after eating [11]. The addition of an ordinary-sized vegetable dish to a meal with a moderately fatty main dish (SMFV meal) causes a different GLP-1 response than does a meal without a vegetable dish (SMF meal) [12]. Mekabu is also reported to contain EPA (eicosapentaenoic acid) [13], and it is conceivable that the EPA contained in Mekabu is partially responsible for its plasma GLP-1 secretion promoting action.

There is a report that the insulin secretion promoting action (incretin effect) of GLP-1 is lower in type 2 diabetes patients [14]. This is why type 2 diabetes patients with insulin resistance are commonly treated with GLP-1 receptor agonists or DPP-4 inhibitors. This study shows that the ingestion of Mekabu causes suppression of postprandial blood glucose levels, combined with a longer period of secretion of GLP-1. By incorporating Mekabu before meals, it can be expected to have an action similar to that of a GLP-1 receptor agonist, so mekabu can be an effective means for prevention and improvement in patients with type 2 diabetes. In addition, GLP-1 has been found to have not only an incretin effect but also an appetite-suppressing effect via the central nervous system [11], and it has been reported that this causes weight loss [15]. Mekabu can be expected not only to prevent and improve diabetes by suppressing the increase in blood glucose level through the incretin effect, but also to prevent obesity by suppressing the appetite.

Although diabetes increases the risk of arteriosclerosis, it has been reported that the risk was reduced in type 2 diabetic patients who received a GLP-1 receptor agonist [16]. The report also suggests a reduced risk of the incidence of microangiopathy such as diabetic retinopathy and diabetic nephropathy. These results 
suggest that ingestion of mekabu, which promotes GLP-1 secretion, may be effective in preventing diabetic complications.

In this study, preprandial intake of Mekabu resulted in suppression of postprandial blood glucose levels. Furthermore, a secretagogue action of plasma GLP-1 was also observed. GLP-1 secreting L cells are abundant in the distal small intestine, but in this study, plasma GLP-1 level tended to be higher at 30 minutes after meals due to ingestion of Mekabu. The reason for this is unclear, and further studies are needed in the future.

\section{CONCLUSION}

This study showed that Mekabu, the sporophyll of wakame intake effectively suppressed postprandial blood glucose level and supported the extended secretion of GLP-1 in healthy subjects. Thus, our results indicate that pre-meal intake of Mekabu could be potentially of regulating blood glucose level in a daily diet.

List of Abbreviations: IDF: Internatinal Diabetes Federation, GLP-1: glucagon-like pepride-1, DPP-4: dipeptidyl peptidese-4, HOMA-IR: Homeostatic Model Assessment for insulin resistance, THC: Takaki Heating and Cooling, SD: standard deviation, BMI: body mass index, AUC: area under the curve, EPA: eicosapentaenoic acid

Authors' Contributions: S.T. performed the analyses and wrote the manuscript; H.K. and N.I. helped writing and critically revising the manuscript. K.Y. and M.T. designed the study, analyzed the data, supervised and contributed fundamental conceptualization for the research, and wrote and edited the manuscript. M.T. had primary responsibility for the final content. All authors read and approved the final version of the manuscript.

Conflict of Interest/Acknowlegment/Funding: Some of this study was conducted using contract research funding from Kaneryo Sea Vegetable Corporation.

\section{REFERENCES}

1. IDF Organization: IDF Diabetes Atlas, 10th edition. Belgium; 2021.

2. Jens JH: The Physiology of Glucagon-like Peptide 1. Physiol Rev 2007, 87:1409-1439. https://doi.org/10.1152/physrev.00034.2006

3. Imai S, Fukui M, Kajiyama S: Effect of eating vegetables before carbohydrates on glucose excursions in patients with type 2 diabetes. J Clin Biochem Nutr 2014, 54: 7-11. https://doi.org/10.3164/jcbn.13-67

4. Alpana PS, Radu Iliescu G., Catherine E. Thomas and Louis J. Aronne. Food Order Has a Significant Impact on Postprandial Glucose and Insulin Levels. Diabetes Care 2015, 38:98-99. https://doi.org/10.2337/dc15-0429

5. Nishimoto K, Sakurai M, Takeshita Y, Takamura T. Consuming Carbohydrates after Meat or Vegetables Lowers Postprandial Excursions of Glucose and Insulin in Nondiabetic Subjects. J Nutr Sci Vitaminol 2018, 64:316-320 https://doi.org/10.3177/insv.64.316

6. Kuwata H, Iwasaki M, Shimizu S, Minami K, Maeda H, Seino S, Nakada K,et al. Meal sequence and glucose excursion, gastric emptying and incretin secretion in type 2 diabetes: a randomised, controlled crossover, exploratory trial. Diabetologia 2016, 59:453-46. https://doi.org/10.1007/s00125-015-3841-z

7. Yoshinaga $\mathrm{K}$, Mitamura $\mathrm{R}$, Effects of Undaria pinnatifida (Wakame) on Postprandial Glycemia and Insulin Levels in Humans: a Randomized Crossover Trial. Plant Foods for Human Nutrition 2019, 74:461-467.

8. IA. Brownlee, A. Allen, JP. Pearson, PW. Dettmar, ME. Habler, MR. Atherton, E. Onsoyen. Alginate as a Source of Dietary Fiber. Critical Reviews in Food Science and Nutrition 2005, 45: 497510.

9. T. Vinoth Kumara, S. Lakshmanasenthila, D. Geetharamanib, T. Marudhupandic, G. Sujaa, P. Suganyaalnternationa. Fucoidan A $\alpha$-d-glucosidase inhibitor from Sargassum wightii with relevance to type 2 diabetes mellitus therapy. Journal of Biological Macromolecules 2015, 72:1044-1047. https://doi.org/10.1016/i.ijbiomac.2014.10.013

10. David. J. A. Jenkins, Thomas M. S. Wolever, Anthony R. Leeds, Miguel A. Gassull, Peter Haisman, Jang Dilawari, David V. Goff, Geoffrey L. Metz, K. G. M. M. Alberti. Dietary fibres, fibre analogues, and glucose tolerance: importance of viscosity. 
British Medical Journal 1978, 1:1392-1394.

https://doi.org/10.1136/bmj.1.6124.1392

11. C. Qualmann, MA. Nauck, JJ. Holst, C. Orskov, W. Creutzfeldt. Glucagon-like peptide 1 (7-36 amide) secretion in response to luminal sucrose from the upper and lower gut. A study using alpha-glucosidase inhibition (acarbose). Scand J Gastroenterol 1995, 30:892-898.

https://doi.org/10.3109/00365529509101597

12. Kameyama K, Mruyama C, Matsui S, Araki R, Yamada Y, Maruyama T. Effects of consumption of main and side dishes with white rice on postprandial glucose, insulin, glucosedependent insulinotropic polypeptide and glucagon-like peptide-1 responses in healthy Japanese men. British Journal of Nutrition 2014, 111:1632-1640.

https://doi.org/10.1017/\$0007114513004194

13. Morishita M, Tanaka T, Shida $T$ and Takayama K, Usefulness of colon targeted DHA and EPA as novel diabetes medications that promote intrinsic GLP-1 secretion. J Control Release 2008, 132: 99-104. https://doi.org/10.1016/j.jconrel.2008.09.001

14. Kirsten V, Husai G, BA. Menge, Oliver G, Carolyn FD, WE. Schmidt, JJ. Holst, Juris J. Meier. Hyperglycemia Acutely Lowers the Postprandial Excursions of Glucagon-Like Peptide-1 and Gastric Inhibitory Polypeptide in Humans. J Clin Endocrinol Metab 2009, 94(4):1379-1385.

https://doi.org/10.1210/jc.2008-2197

15. Kaji I, Karaki S, Kuwahara A. The role of postprandial releases of insulin and incretin hormones in meal-induced satiety-effect of obesity and weight reduction. International Journal of Obesity 2001, 25:1206-1214.

https://doi.org/10.1038/sj.ijo.0801655

16. Gerstein HC, Colhoun HM, Dagenais GR, Diaz R, Lakshmanan M, Pais P, Probstfield J, et al. Dulaglutide and cardiovascular outcomes in type 2 diabetes (REWIND): a double-blind, randomised placebo-controlled trial. The Lancet 2019, 394:121-130.

https://doi.org/10.1016/S0140-6736(19)31149-3 